\title{
PIK3CB Gene Mutation
}

National Cancer Institute

\section{Source}

National Cancer Institute. PIK3CB Gene Mutation. NCI Thesaurus. Code C141340.

A change in the nucleotide sequence of the PIK3CB gene. 